\title{
Local air pollutants threaten Lake Tahoe's clarity
}

\author{
by Alan W. Gertler, Andrzej Bytnerowicz, \\ Thomas A. Cahill, Michael Arbaugh, \\ Steven Cliff, Jülide Kahyaoğlu-Koračin, \\ Leland Tarnay, Rocio Alonso and Witold Fraczek
}

Lake Tahoe is a high-altitude $(6,227$ feet) lake located in the northern Sierra Nevada at the CaliforniaNevada border. During the second half of the 20th century, the decline in Lake Tahoe's water clarity and degradation of the basin's air quality became major concerns. The loading of gaseous and particulate nitrogen, phosphorus and fine soil via direct atmospheric deposition into the lake has been implicated in its eutrophication. Previous estimates suggest that atmospheric nitrogen deposition contributes half of the total nitrogen and a quarter of the total phosphorus loading to the lake, but the sources of the atmospheric pollutants remain unclear. In order to better understand the origins of atmospheric pollutants contributing to the decline in Lake Tahoe's water clarity, we reviewed a series of studies performed by research groups from the U.S. Department of Agriculture's Forest Service, UC Davis and the Desert Research Institute. Overall, the studies found that the pollutants most closely connected to the decline in Lake Tahoe's water quality originated largely from within the basin.

he Lake Tahoe Basin is a subalpine
ecosystem bordered by the Carson Range to the east (Nevada) and the Sierra Nevada crest to the west (California). This 520-square-mile basin is dominated by the 192-square-mile Lake Tahoe, which is noted for its exceptionally clear water. The lake's water clarity is largely due to nutrient-poor granitic soils in the surrounding watershed and

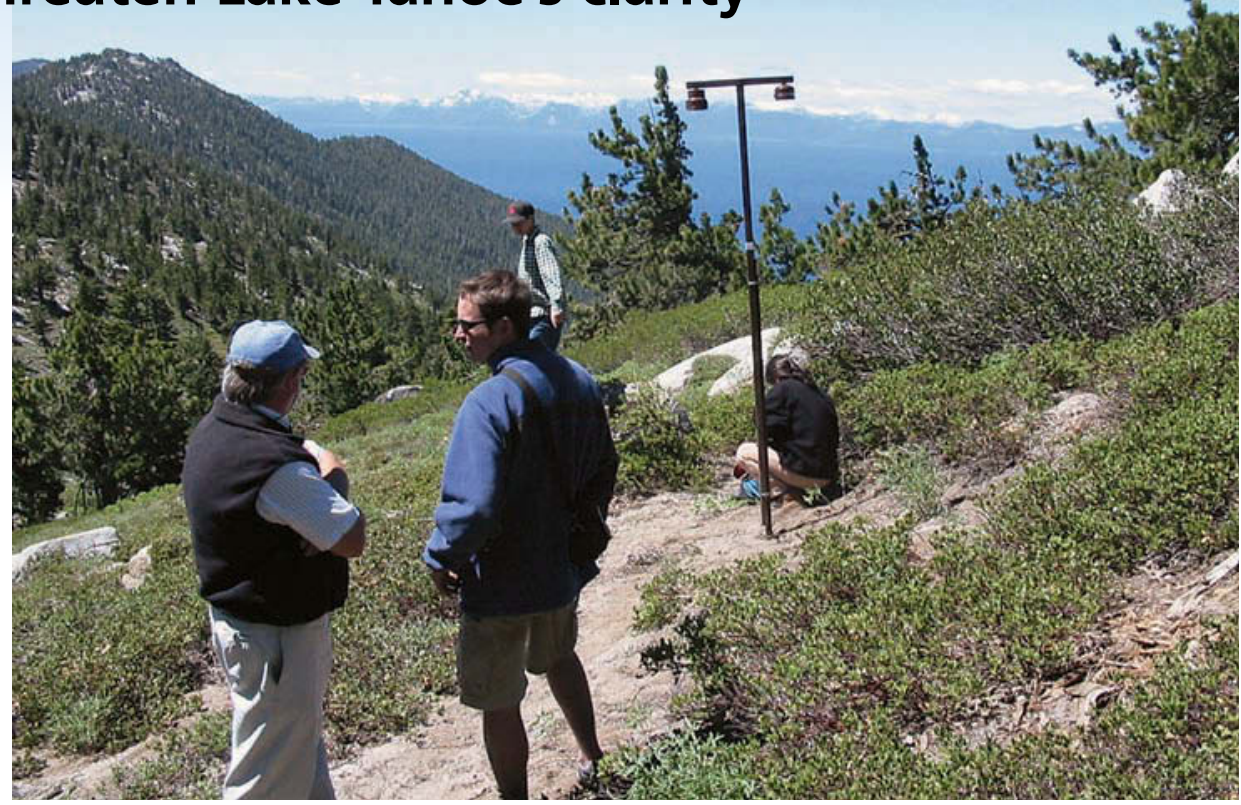

In 2002, scientists constructed passive samplers throughout the Tahoe Basin, including, above, on Diamond Peak, to measure 2-week average ozone and nitric acid concentrations. Air pollutants are believed to be an important contributor to Lake Tahoe's declining clarity.

a low watershed-to-lake ratio. Most of the rest of the basin is a nitrogen-poor, mixed-conifer forest ecosystem comprised mainly of fir (red [Abies magnifica] and white [Abies concolor ]), pine (lodgepole [Pinus contorta], sugar [Pinus lambertiana] and Jeffrey [Pinus jeffreyi]), and incense cedar (Calocedrus decurrens). Historically, these factors have minimized the flow into the lake of nutrients and sediment that could reduce water clarity.

Since 1967, Lake Tahoe's water quality has declined at an unexpectedly rapid rate, in part due to anthropogenic nutrient and sediment loading (Goldman 1988; Jassby et al. 1999; Murphy and Knopp 2000). The Lake Tahoe Watershed Assessment provided a comprehensive summary of scientific knowledge regarding the factors contributing to the observed water-quality decline and the steps that can be taken to restore the Lake Tahoe Basin ecosystem (Murphy and Knopp 2000). Contributing factors include nitrogen, phosphorus and sediment flow into Lake Tahoe. Murphy and Knopp (2000) reported that atmospheric deposition (gases and particles that enter the lake from the air) accounts for approximately $55 \%$ of the nitrogen and $27 \%$ of the phosphorus load into the lake. No estimate of atmospheric fine-soil particulate input was presented.

\section{GLOSSARY}

CALMET/CALPUFF air-quality modeling system: A meteorological and air-quality model adopted by the U.S. Environmental Protection Agency as the preferred model for assessing the longrange transport of pollutants.

Eutrophication: The process by which water bodies receive excess nutrients that can stimulate plant and algal growth.

Foliar injury: Injury of tree foliage caused by exposure to elevated concentrations of ambient ozone.

Nested domains: Different-sized geographical areas used in the modeling system. To reduce computational requirements, the outer domain is modeled using larger areas, while the resolution is enhanced for the inner (nested) regions of interest.

Prognostic numerical weather model (MM5): The Fifth-Generation Penn State/ National Center for Atmospheric Research meteorological model. This model is used to predict wind speed and direction for use in other modeling systems such as CALMET/CALPUFF.

Sensitivity studies: Tests performed as part of the modeling validation process to assess which variables can affect model performance.

Synoptic: Reflecting overall patterns derived from data obtained simultaneously from points across a wide area. 


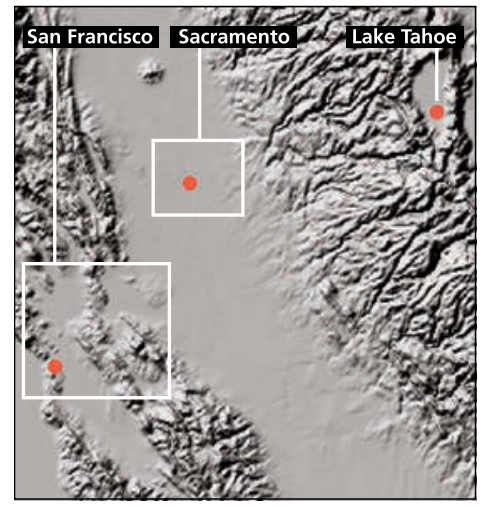

In addition to decreasing water clarity, atmospheric pollutants can affect forest health. It is well established that ambient ozone has pronounced adverse effects on forest health in California's mountain regions (Arbaugh et al. 1998). According to large-scale distribution maps of the Sierra Nevada bioregion, the Lake Tahoe Basin's summer-season, 24-hour ozone levels are 50 parts per billion (ppb) to $60 \mathrm{ppb}$ (Fraczek et al. 2003). Such ozone levels may be phytotoxic (toxic to vegetation) (Krupa et al. 1998) and can adversely affect tree health (Arbaugh et al. 1998). Ozone causes foliar injury (an indicator of tree health) to ponderosa (Pinus ponderosa) and Jeffrey pines in the central Sierra Nevada (Miller et al. 1996),

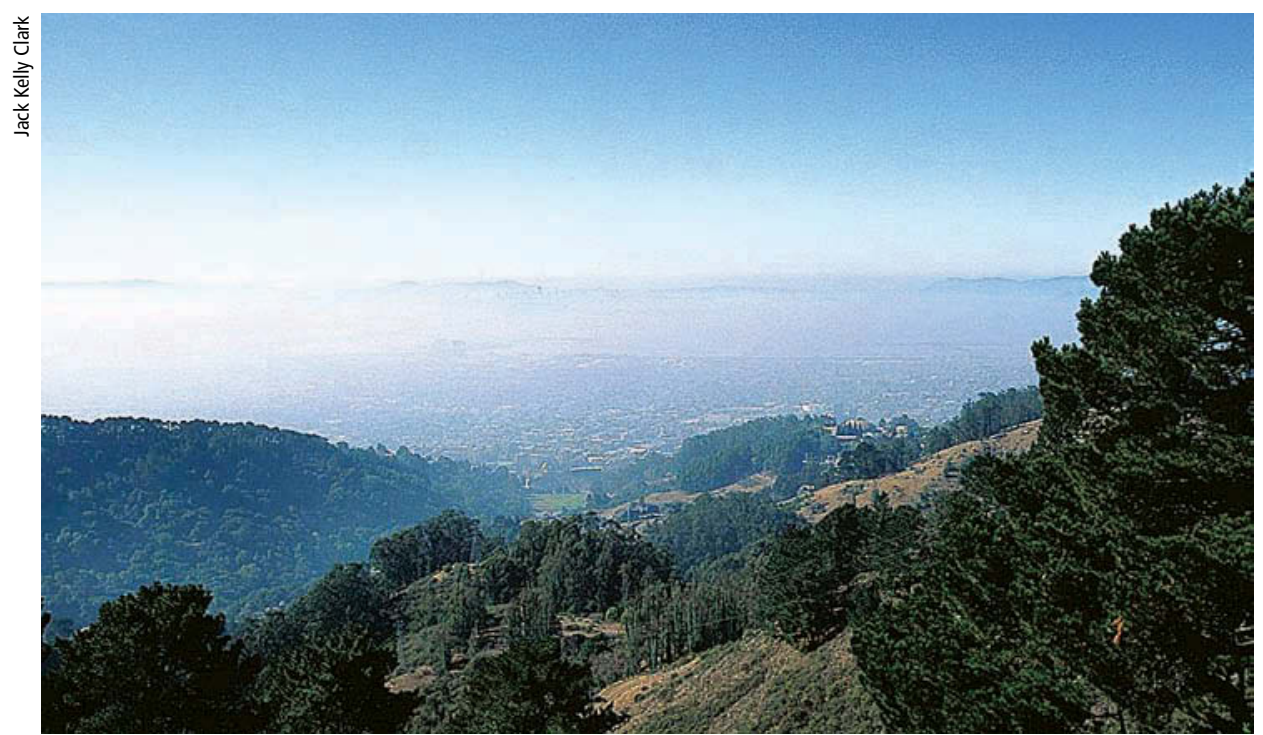

Using atmospheric models, the authors simulated how air pollutants from the Bay Area, above, and Sacramento Valley are affecting the Tahoe Basin. While pollutants are transported from outside the basin, the model suggests that they are significantly diluted by mixing on the western slopes of Sierra Nevada.
Fig. 1. (A) Area of California modeled, with emissions sources (San Francisco Bay Area, Sacramento and Lake Tahoe Basin). (B) In the Lake Tahoe Basin, blue circles designate point sources used to represent mobile and area emission sources. Marked stations are South Lake Tahoe (SOLA), Bliss State Park (BLIS), Thunderbird Lodge (TBLG), Echo Summit (ECHO), U.S. Coast Guard (USCG) and Barker Pass (BARK).

\section{Modeling nitrogen pollution}

In terms of hemispheric atmospheric circulations, California is within the latitude range of prevailing westerly winds. However, due to the relatively weak effect of large-scale atmospheric motions, wind patterns tend to be modified by the differential heating between the land and ocean. Previous studies have shown that in California's typical summer wind-flow pattern, marine air penetrates through the Carquinez Strait (in the northeastern San Francisco Bay) and bifurcates around the Bay's Delta region into south and north branches (Moore et al. 1987; Zaremba and Carroll 1999). This primary pattern is superimposed by thermally driven daytime upslope and nighttime downslope flows, making pollutant transport eastward possible from heavily polluted regions, such as the San Francisco Bay Area and the Sacramento Valley, up into the Sierra Nevada.

In order to quantify how much nitrogen these winds bring into the Tahoe Basin, we used the advanced numerical atmospheric models CALMET/ CALPUFF (Scire et al. 2000) and MM5 (Grell et al. 1995) to estimate the contributions from both in-basin (such as cars and trucks) and out-of-basin (such as industry, cars and trucks) nitrogen sources. The area we modeled was selected to simulate how the basin's air is affected by pollutant transport from the Sacramento Valley and San Francisco Bay Area (fig. 1A).

In this study, the comprehensive CALMET/CALPUFF air-quality modeling system was coupled with a numerical weather model called MM5. The output from the MM5 model was coupled with available surface and upperair meteorological measurements to enhance the accuracy of the predictions (fig. 1B). The CALMET / CALPUFF simulation grid (fig. 1A) contained 250by-265 cells, each 1 square kilometer (0.61 square miles), and the lower 

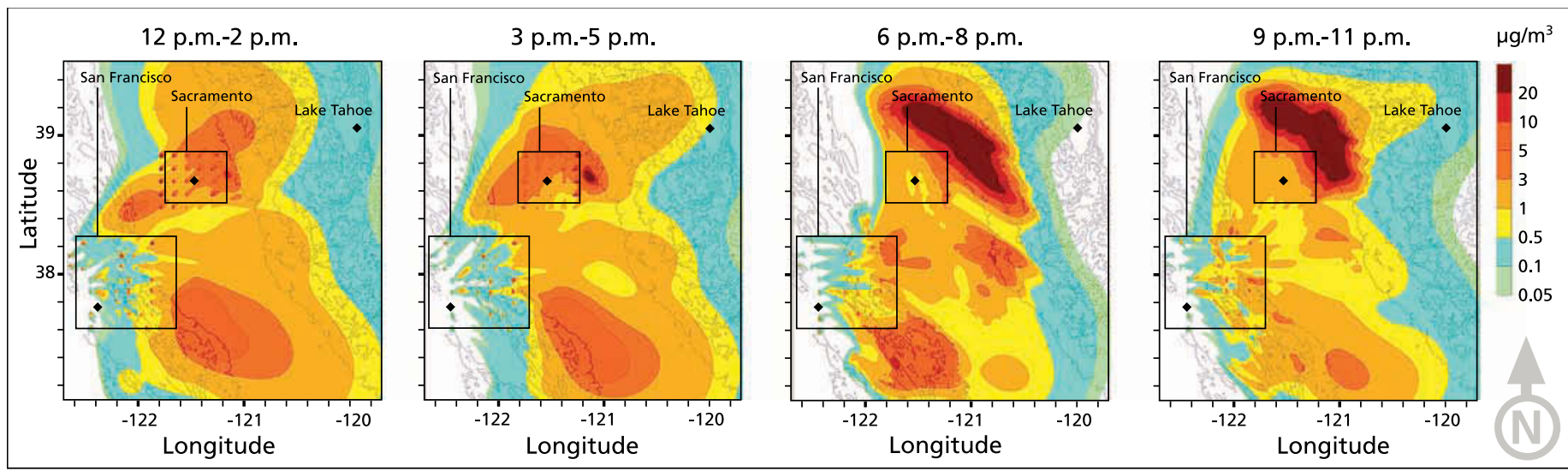

left grid corner was referenced at $37.10^{\circ}$ $\mathrm{N}$ and $122.70^{\circ} \mathrm{W}$.

In order to accurately predict regional versus local transport and dispersion, information on pollutant (such as oxides of nitrogen) emission rates was critical. This data was obtained from the California Air Resources Board (CARB). For the Lake Tahoe Basin, we prepared hourly emission allocations based on the CARB inventory. Hourly emissions from Truckee, Reno, Interstate 395 and the west Sierra foothills were also included. Sensitivity studies were performed for the model calibration.

One of the key pollutants leading to nitrogen deposition into the lake is nitric acid $\left(\mathrm{HNO}_{3}\right)$. This pollutant is not directly emitted from sources but is formed through a series of atmospheric reactions involving oxides of nitrogen and hydrocarbons. Estimates of nitric acid formation and atmospheric concentrations were made using the previously described modeling system.

Simulations were performed for three selected cases coinciding with previous nitric acid measurements during summer 2000 (Tarnay et al. 2001, 2005). These cases were selected based on a range of wind patterns and high/low ambient nitric acid. Analysis of surface observations (surface wind frequencies and precipitation) and large-scale synoptic pressure systems (500 millibar wind and pressure maps) showed that the selected cases were climatologically representative of summer 2000. MM5 simulations were performed with twoway nesting for a 4-day period. The spin-up time was 12 hours. In order to model regional-scale transport and reduce the effect of boundary conditions, the CALMET/CALPUFF modeling system was run for 72 hours for each of the selected cases.

Fig. 2. Evolution of nitric acid $\left(\mu \mathrm{g} / \mathrm{m}^{3}\right)$ plume from California's Central Valley, Aug. 28, 2000. Concentrations (filled contours overlaid with topography) are averaged over 3-hour intervals. The enclosed areas surrounding Sacramento and San Francisco regions designate the emission sources. Note the effects of daytime upslope flows and nighttime downslope flows; pollutant concentrations at elevated regions are low, implying minimal nitric acid transport to the Lake Tahoe Basin.

\section{Airborne plume mostly diluted}

The overall simulation results indicated that there is pollutant transport from the Sacramento Valley and San Francisco Bay Area to the Lake Tahoe Basin (fig. 2). However, these pollutant concentrations were significantly diluted by mixing with other air masses on the west slopes of the Sierra Nevada at increasing elevations, as measured in previous studies (Carroll and Dixon 2002; Dillon et al. 2002; Bytnerowicz et al. 2002). While part of the emissions plume can progress over the Sierra Nevada to the Lake Tahoe Basin, nitric-acid ambient air concentrations are extremely low. In addition, later in the day, downslope winds carry the plume back to the Central Valley. (Simulations of in-basin and outof-basin emissions were performed separately in order to determine their relative contributions; the impact from in-basin emissions is not shown in figure 2.)

On the other hand, the results also showed that the predicted nitric acid concentrations due to local sources were in good agreement with actual measurements. For example, $90 \%$ of the predicted nitric acid concentrations were due to local sources, and the predicted concentrations comprised $65 \%$ of the average measured values (Tarnay et al. 2001) in all the monitoring locations around Lake Tahoe. Emissions of nitrogen oxides from other nearby source regions such as Reno and Interstate 80 were two to three orders of magnitude smaller than those from the San Francisco Bay Area and the Sacramento Valley, and had no significant predicted impact.

In short, while the results of this work suggest that daytime pollutant transport from upwind of the Lake Tahoe Basin appears to be likely, the amount of nitric acid transported from outside of the basin is much less than that from in-basin sources. In order to better quantify these contributions, additional study is needed on long-term transport effects under different meteorological patterns that could lead to increased transport to the basin.

\section{Measuring ozone and nitric acid}

On-ground monitoring of pollutant concentrations helps to test the results of the modeled air-pollution distribution predictions. One of the great difficulties in evaluating the transport of air pollut- 


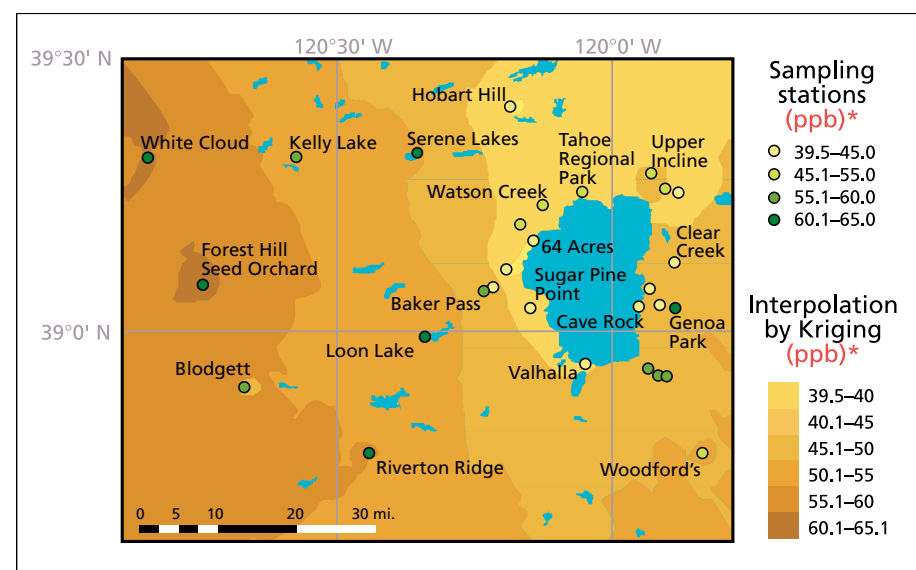

Fig. 3. Seasonal average distribution of ambient ozone concentrations $(\mathrm{ppb})^{*}$ in the Lake Tahoe Basin and its vicinity, summer 2002. Shaded areas represent concentrations determined by interpolation of the observed data by Kriging. Maximum levels of ozone were observed to the west of the lake, but are not transported to the basin.

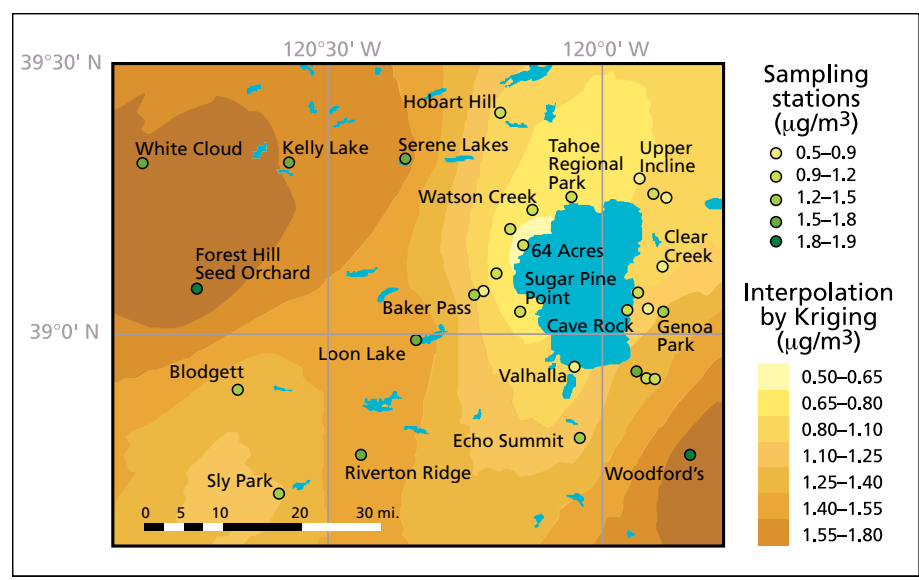

Fig. 4. Seasonal average distribution of ambient nitric acid concentrations $\left(\mu \mathrm{g} / \mathrm{m}^{3}\right)$ in the Lake Tahoe Basin and its vicinity, summer 2002. Maximum levels were observed west of the Sierra Nevada crest and lowest levels are near the west shore of the lake.
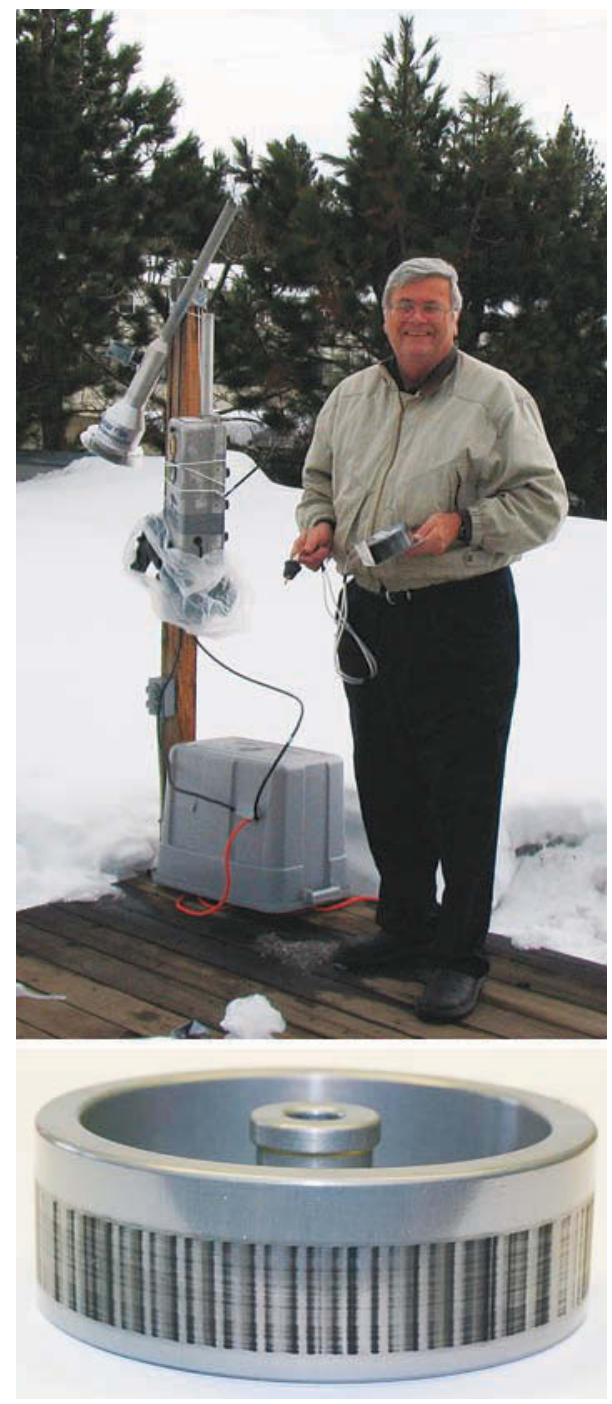

Top, UC Davis professor Tom Cahill sets up a DRUM sampler at South Lake Tahoe. Bottom, the sampler shows the pattern of very fine, phosphorus-rich aerosols collected over a 3-week period. The dark bands occur in the morning and evening, when the wind stagnates. known to transport into the basin, and nitric acid. We selected 32 monitoring sites to assess air pollution levels in and around the Lake Tahoe Basin. The sites were selected in open terrain located on a western aspect, with free air movement from all directions. The passive samplers measured 2-week average ozone and nitric acid concentrations throughout the 2002 smog season.

Pollutant distribution maps were developed with geostatistical software (ARC/INFO Geostatistical Analyst; ESRI, Redlands, Calif.) that uses values measured at sample points at different locations in the landscape and interpolates them into a continuous surface. Using a set of measurements in a given study area, a spatial model of ozone concentration was constructed (Fraczek et al. 2003). Techniques were then used to develop prediction maps of the air pollutant's distribution for each individual 2 -week sampling period and for the entire season.

The highest 2-week and wholeseason average ozone and nitric acid concentrations occurred in the Sacramento foothills, west of the Lake Tahoe Basin. Concentrations of these pollutants were much lower near the lake, especially near the west shore. It appears that the mountain range west of the Lake Tahoe Basin (Desolation Wilderness) impedes the westerly flow of low-layer polluted air masses from the Sacramento metropolitan area and the Sierra Nevada foothills, limiting pollutant transport into the basin. East of the lake, ozone and nitric acid levels generally increased with distance from the South Lake Tahoe community urban area.

Over the course of smog season, there was a clear pattern in ozone and nitric acid concentrations. For the entire study area, the lowest levels occurred during the first halves of July and October, and the highest levels occurred during the second half of August (figs. 3 and 4). The highest levels of ozone and nitric acid in August coincide with traffic-related high emissions of nitrogen oxides and volatile organic compounds (VOC), high temperatures and solar radiation - all factors promoting the generation of these photochemically produced air pollutants.

\section{Foliar injury rates low}

To estimate the effects of elevated ozone on forest health, we reviewed the results of studies conducted by the USDA Forest Service in the 1970s. USDA scientists conducted studies to evaluate foliar injury, applying the Ozone Injury Index (OII) methodology, in the Sierra Nevada and the San Bernardino mountains (Miller et al. 1996). Foliar ozone injury was evaluated at 25 preexisting study sites in the Lake Tahoe Basin. The sites were originally established in the late 1970s to each contain 15 mature ponderosa pine trees, but as few as six of the original trees remained at some of the locations by the time of the foliar-injury evaluation study.

Overall, 23\% of the trees evaluated had foliar ozone injury but the average OII was only 17.3 (100 indicates the highest level of injury), which shows that the injury occurring to the pines in 


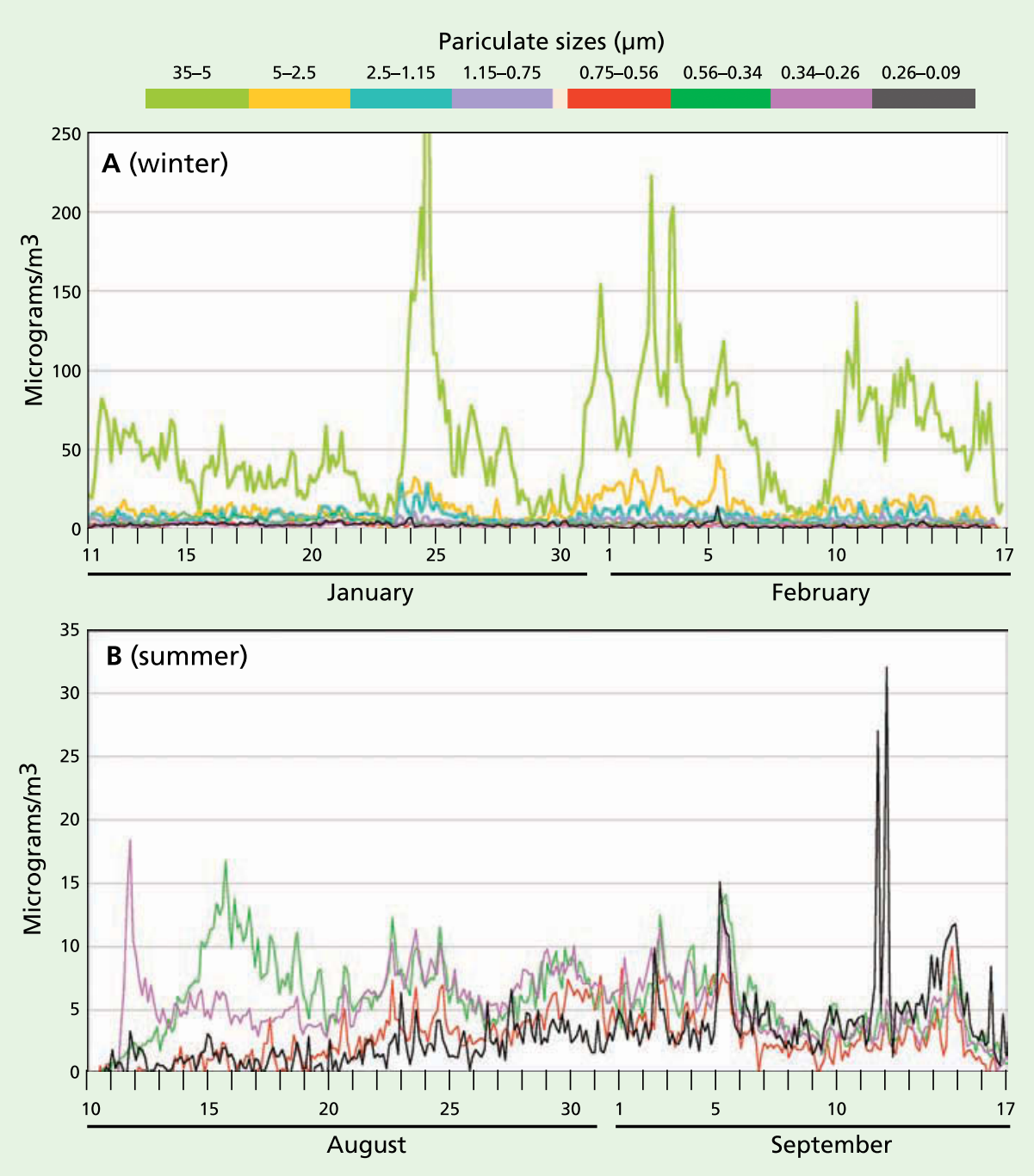

Fig. 5. Size-segregated phosphorus measurements $\left(\mu \mathrm{g} / \mathrm{m}^{3}\right)$ in 2002 for (A) winter (eight particulate size fractions) and (B) summer (four fine particulate size fractions to better show smoke and exhaust). The maximum levels of phosphorus were observed in the largest size fractions, winter and summer, indicating that resuspended geological material was the major pollutant source.

this area is slight. In addition, no discernible spatial patterns of injury were observed between sites, so the degree of ozone injury likely depends on microsite growing conditions as well as on the genotypic and phenotypic responses of individual trees to ozone air pollution.

\section{Measuring phosphorus}

Phosphorus, which comes into the lake from both sediment in stream runoff and airborne particles, is presently the limiting nutrient for algal growth, a major factor in the lake's clarity decline; while all pollutants entering Lake Tahoe must be reduced, nitrogen pollution is currently so high that the most effective strategy for the time being is to reduce phosphorus. About one-fourth of all phosphorus comes from the air, as shown by the phospho- rus data from deposition buckets on and near the lake, but phosphorus is rarely seen in the existing ambient air samples. One possibility is that phosphorus occurs in particles larger than those collected by current in-basin, filter-based air samplers, which only measure fine particles below $2.5 \mathrm{mi}$ crons $(\mu \mathrm{m})$ in diameter.

In order to assess the airborne sources of phosphorus, measurements were performed in January and August 2002 using a particulate sampler developed at UC Davis (Cahill and Wakabayashi 1993). In contrast to filterbased measurements, this sampler allowed for measuring particles in eight size-segregated fractions, ranging from $35 \mu \mathrm{m}$ (roughly a high-volume [HiVol] inlet to catch coarse soil aerosols) to $0.09 \mu \mathrm{m}$ (to catch diesel and smok-
TABLE 1. Sources and estimated tonnage of phosphorus deposition in the Lake Tahoe Basin

\begin{tabular}{ll}
\hline \hline Transported & Ton/year \\
\hline Asian dust & $0.6-1.0$ \\
Sacramento Valley dust & $0.12-0.6$ \\
Oregon forest fire smoke (2002) & $0.2-0.3$ \\
Local & \\
\hline Highway road dust (winter) & $3.5-5.0$ \\
Local soils (spring to fall) & $1.5-4.5$ \\
Vehicle exhaust & $1.2-1.8$ \\
Local wood smoke & $0.3-0.5$ \\
\hline
\end{tabular}

ing car exhaust). In addition, the UC Davis particulate sampler allowed for better source identification because it has a high time resolution (3 hours). Finally, this sampler resulted in an order of magnitude better detection of phosphorus than the filters (Bench et al. 2002) because elemental analysis for phosphorus was performed by synchrotron X-ray fluorescence (S-XRF). Samples were collected at the South Lake Tahoe site for 12 weeks in winter and 6 weeks in summer to allow analysis of synoptic weather patterns.

Most of the phosphorus observed during the winter and summer occurred between the 2.5 and $35 \mu \mathrm{m}$ size fractions, consistent with the sources being resuspended road dust and soil (fig. 5). Previous studies in the area used samplers with a $2.5-\mu \mathrm{m}$ upper cut-point and would have missed this contribution. This implies that most of the phosphorus comes from in-basin sources, since particles in this range tend to deposit rapidly and so are rarely transported far in the atmosphere. We can estimate the phosphorus deposition from a range of sources based on these particulate sampler data and earlier data using the Lake Tahoe Airshed Model (LTAM) (Cahill and Cliff 2000) and estimated deposition velocities (Seinfeld and Pandis 1998) (table 1).

While these results are highly uncertain, especially because they are based on a single, near-roadway South Lake Tahoe site, together they imply that the majority of phosphorus deposition in the Tahoe Basin can be attributed to local sources from roadway sanding and salting in winter, local soils in summer and vehicle exhaust. Furthermore, some of the out-of-basin sources may not occur routinely. The 2002 Oregon forest fires were unusually severe, and showed a high phosphorus content not seen in 
less violent fires such as prescribed burns (Turn et al. 1997). The Asian dust values in particular are uncertain and highly variable from year to year, depending on the strength of the dust storms in Asia and the location of the Pacific highpressure system and winds, which can push Asian dust north into Canada and cut off transport to California, as happened in 2003. It should also be noted that these measurements represent total phosphorus, as opposed to bioavailable phosphorus, and thus have uncertain impacts on algal growth.

\section{Sources of Tahoe air pollutants}

Taken together, our review of several important studies indicates that out-of-basin sources are not the major contributors to the observed levels of air pollutants in the Lake Tahoe Basin. For example, the advanced numerical modeling approach found that $90 \%$ of predicted nitric acid in the basin came from precursors emitted within the ba$\sin$. The models attributed the minimal contribution from out-of-basin sources to a number of factors, including dilution, dispersion and minimal pollutant flow into the basin. Similar conclusions were reached by the studies investigating forest health and the sources of phosphorus in the Lake Tahoe Basin. Based on these findings, the most effective strategy to reduce the impact of atmospheric deposition on the lake's clarity and in-basin forest health would be to control local pollutant emissions.

\section{A.W. Gertler is Research Professor and}

J. Kahyaoğlu-Koračin is Postdoctoral Research Associate, Desert Research Institute, Reno, Nev.; A. Bytnerowicz and M. Arbaugh are Ecologists, USDA Forest Service, Riverside; T.A. Cahill is Professor, Physics and Atmospheric Sciences, and S. Cliff is Research Professor, Department of Applied Sciences, UC Davis; L. Tarnay is Physical Scientist and Air Resources Specialist, National Park Service, Yosemite National Park; R. Alonso is Plant Physiologist, Ecotoxicology of Air Pollution, CIEMAT, Madrid, Spain; and W. Fraczek is Application Prototype Specialist, Environmental Systems Research Institute, Redlands, Calif. T.A. Cahill and S. Cliff wish to acknowledge the support of the Tahoe Regional Planning Agency for the aerosol measurement program. J. Kahyaoğlu-Koračin would like to acknowledge the assistantship provided by NSF ACES and thank Geoffrey Schladow of UC Davis for providing meteorological data. A. Bytnerowicz,

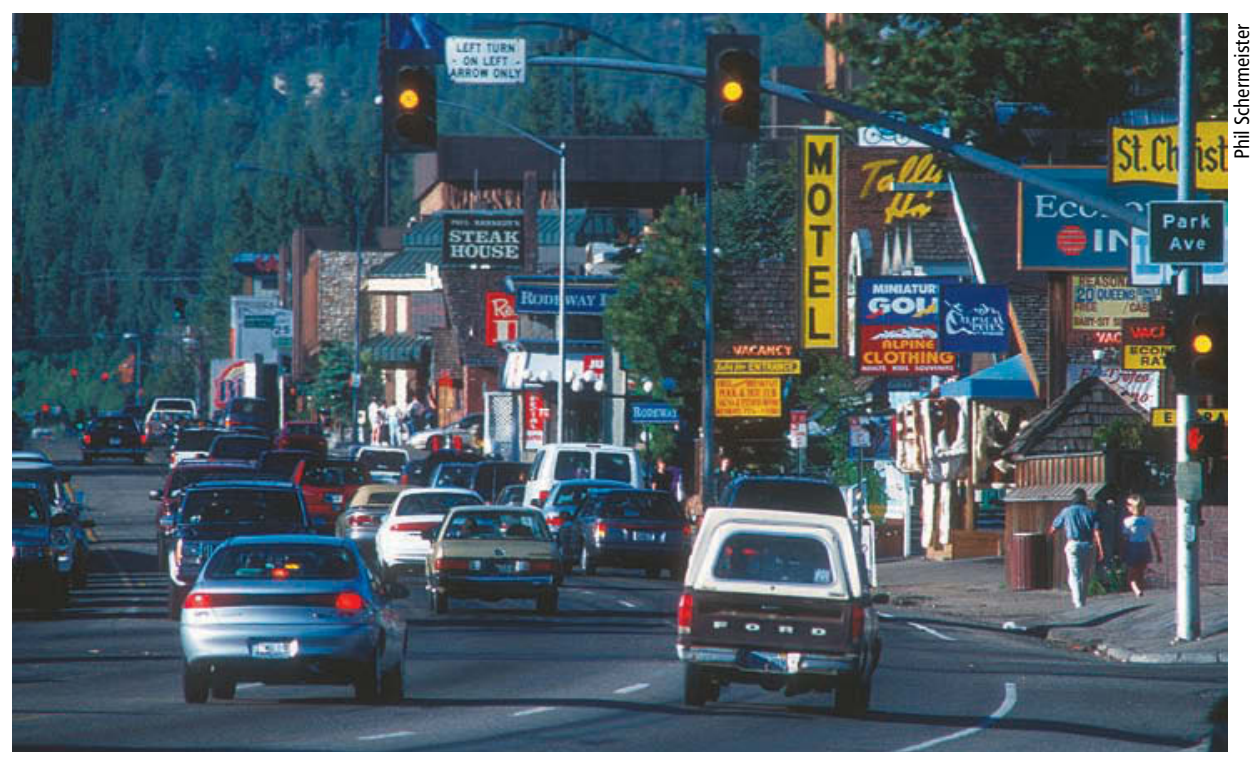

Out-of-basin pollutants are not the major contributors to air pollution in the Tahoe Basin; rather, local sources are having the most significant effects on air and water quality, and forest health. Above, Highway 50 in South Lake Tahoe.

M. Arbaugh, R. Alonso and W. Fraczek thank Trent Proctor (USDA Forest Service) and Brent Takomoto (California Air Resources Board) for their assistance and support.

\section{References}

Arbaugh MJ, Miller PR, Carroll J, et al. 1998. Relationship of ambient ozone with injury to pines in the Sierra Nevada and San Bernardino mountains of California, USA. Environ Pollution 101:291-301.

Bench, G, Grant PG, Ueda D, et al. 2002. The use of STIM and PESA to respectively measure profiles of aerosol mass and hydrogen content across Mylar rotating drum impactor samples. Aerosol Sci Technol 36:642-51.

Bytnerowicz A, Tausz M, Alonso R, et al. 2002 Summer-time distribution of air pollutants in Sequoia National Park, California. Environ Pollution 118(2):187203.

Cahill TA, Cliff SS. 2000. Air quality (ch 3). In: Murphy and Knopp (eds.). The Lake Tahoe Watershed Asses sment Report. USFS Pacific Southwest Research Station. Gen Tech Rep No. PSW-GTR-175. 736 p.

Cahill TA, Wakabayashi P. 1993. Compositional analysis of size-segregated aerosol samples. In: Newman $\mathrm{L}$ (ed.). Measurement Challenges in Atmospheric Chemistry. ACS Pubs. p 211-28.

Carroll JJ, Dixon AJ. 2002. Regional scale transport over complex terrain, a case study: Tracing the Sacramento plume in the Sierra Nevada of California. Atmospher Environ 36(23):3745-58.

Dillon MB, Lamanna MS, Schade GW, Goldstein AH. 2002. Chemical evolution of the Sacramento urban plume: Transport and oxidation. J Geophys Res 107(D5):1-15.

Fraczek W, Bytnerowicz A, Arbaugh MJ. 2003. Use of geostatistics to estimate surface ozone patterns. In: Bytnerowicz A, Arbaugh MJ, Alonso R (eds.). Ozone Air Pollution in the Sierra Nevada: Distribution and Effects on Forests, Developments in Environmental Science 2. Amsterdam: Elsevier. p 215-47.

Goldman CR. 1988. Primary productivity, nutrients, and transparency during the early onset of eutrophication in ultra oligotrophic Lake Tahoe, California-Nevada. Limnol Oceanogr 33:1321-33.

Grell GA, Dudhia J, Stauffer DR. 1995. A Description of the Fifth Generation Penn State/NCAR Mesoscale Model (MM5). National Center for Atmospheric Research Tech Note, Boulder, CO. 122 p.

Jassby AD, Goldman CR, Reuter JE, Richards RC. 1999. Origins and scale dependence of temporal vari- ability in the transparency of Lake Tahoe, CaliforniaNevada. Limnol Oceanogr 44:282-94.

Krupa SV, Tonneijck AEG, Manning WJ. 1998. Ozone. In: Flagler RB (ed.). Recognition of Air Pollution Injury to Vegetation. Air and Waste Management Assoc. $\mathrm{p}(2) 1-28$.

Miller PR, Guthrey R, Schilling S, Carroll J. 1996. Ozone injury responses of ponderosa and Jeffrey pine in the Sierra Nevada and San Bernardino mountains in California. In: Bytnerowicz A, Arbaugh MJ, Schilling S (eds.). Proc Int Symp Air Pollution and Climate Change Effects on Forest Ecosystems (Feb. 5-9, 1996, Riverside, CA). USDA Forest Service, Gen Tech Rep No. PSW-GTR-166.

Moore GE, Daly C, Liu MK, Huang SJ. 1987. Modeling of mountain-valley wind fields in the southern San Joaquin Valley, California. J Climate Appl Meteorol 26:1230-42.

Murphy DD, Knopp CM (eds.). 2000. Lake Tahoe Watershed Assessment: Vol. I. USDA Forest Service, Pacific Southwest Research Station, Albany, CA. Gen Tech Rep No PSW-GTR-175. 736 p.

[NWRA] Nevada Water Resources Association. 2004 2nd Biennial Conference on Tahoe Environmental Concerns, Crystal Bay, NV-CA, May 17-19.

Pedersen BS. 1989. Ozone injury to Jeffrey and ponderosa pines surrounding Lake Tahoe, California and Nevada. In: Olson RK, Lefohn AS (eds.). Effects of Air Pollution on Western Forests. Air Waste Management Assoc, Transactions Ser No 16, p 279-92.

Scire JS, Strimaitis DJ, Yamartino, RJ. 2000. A User's Guide for the CALPUFF Dispersion Model. Concord, MA Earth Tech. 521 p.

Seinfeld JH, Pandis SN. 1998. Atmospheric Chemistry and Physics. Wiley Interscience. 1,326 p.

Tarnay L, Gertler AW, Blank RR, Taylor GE. 2001. Preliminary measurements of summer nitric acid and ammonia concentration in the Lake Tahoe basin airshed: Implications for dry deposition of atmospheric nitrogen. Environ Pollution 113:145-53.

Tarnay L, Johnson D, Gertler AW. 2005. Modeled inputs of atmospheric nitrogen to the Lake Tahoe Basin due to gaseous pollutant deposition. Journal Nevada Water Resources Assoc 2:41-57.

Turn SQ, Jenkins BM, Chow JC, et al. 1997. Elemental characterization of particulate matter emitted from biomass burning: Wind tunnel derived source profiles for herbaceous and wood fuels. J Geophysic Res 102:3683-99.

Zaremba LL, Carroll JJ. 1999. Summer wind flow regimes over the Sacramento Valley. J Appl Meteorol 38:1463-73. 